\title{
Effect of Lanthanum Cerium Cysteine on Cure Characteristics, Mechanical Properties, and Thermooxidative Aging for Natural Rubber
}

\author{
Wentao Zhang, ${ }^{1,2,3}$ Zhaogang Liu $\mathbb{D}^{1,2,3}$ Shuai Li, ${ }^{1,2,3}$ Wei Hao, ${ }^{1,2,3}$ Yanhong Hu, ${ }^{1,2,3}$ \\ and Jinxiu $\mathrm{Wu}^{1,2,3}$ \\ ${ }^{1}$ School of Materials and Metallurgy, Inner Mongolia University of Science and Technology, Baotou 014010, China \\ ${ }^{2}$ Key Laboratory of Green Extraction \& Efficient Utilization of Light Rare-Earth Resources Ministry of Education, \\ Baotou 014010, China \\ ${ }^{3}$ Inner Mongolia Key Laboratory of Rare Earth Hydrometallurgy and Light Rare Earth Application, Baotou 014010, China
}

Correspondence should be addressed to Zhaogang Liu; liuzg65@163.com

Received 21 October 2021; Revised 23 November 2021; Accepted 24 November 2021; Published 3 December 2021

Academic Editor: Pierre Verge

Copyright (c) 2021 Wentao Zhang et al. This is an open access article distributed under the Creative Commons Attribution License, which permits unrestricted use, distribution, and reproduction in any medium, provided the original work is properly cited.

\begin{abstract}
In this work, a novel additive lanthanum cerium cysteine (LC-Cys), with the molecular formula $\mathrm{La}_{0.35} \mathrm{Ce}_{0.65}(\mathrm{Cys}){ }_{3} \mathrm{Cl} \cdot 3 \mathrm{H}_{2} \mathrm{O}$, was successfully synthesized through complex decomposition reaction of L-Cysteine and chlorinated rare earths. The effects of additive LC-Cys on cure characteristics, mechanical properties, and thermooxidative aging were investigated. LC-Cys as a multifunctional additive was applied to increase the curing rate and reduce the content of zinc oxide in the presence of the sulfur vulcanization system. It was found that the vulcanizates filled with (5ZnO/2LC-Cys) exhibited the highest modulus, which indirectly indicated the high crosslink and stiffness of the vulcanizates. Moreover, the vulcanizates with LC-Cys showed excellent mechanical properties and resistance to thermooxidative aging. Compared to NR composites filled with normal $\mathrm{ZnO}$, LC-Cys even enhanced the mechanical strength and thermooxidative aging properties with $40 \%$ lower $\mathrm{ZnO}$ addition.
\end{abstract}

\section{Introduction}

Vulcanization is a process for preparing elastomeric materials that involves linking several chain-like molecules to form a molecular network structure $[1,2]$. From a chemical point of view, this process involves creating a threedimensional structural network for the vulcanized rubber, in which formation of crosslinking bonds links the rubber macromolecules. Besides sulfur, other additives are often used to guarantee that the vulcanization process is carried out properly. Accelerators and activators are the most familiar and indispensable additives. In the vulcanization process, the selection of the accelerator determines the diversity of the network structure and the nature of the substances. Accelerators can improve the curing speed and the processing safety and even enhance the quantity and type of crosslinking generation. However, it should be noted that traditional accelerators such as tetramethylthiuram disulfide (TMTD), while promoting vulcanization reaction and strengthening the mechanical properties of rubber, can also give rise to carcinogenic nitrosamine generation, which is a hazard to human health and environment safety [3].

Samarasinghe et al. reported a new accelerator diisopropyl xanthogen polysulfide (Dixp) [4]. Dixp was a nitrogenfree accelerator that provided a measure to eliminate or reduce the formation of nitrosamines. Dixp alone as an accelerator showed satisfactory curing time, and the vulcanizate containing the Dixp/TBBS binary curing system exhibited excellent synergistic effect in terms of cure characteristics and mechanical properties.

2-Mercaptobenzothiazole rare-earth accelerator was synthesized by Wei et al. in anhydrous ethanol [5]. Compared with the conventional tire accelerator 2-(4-morpholinothio)-benzothiazole (NOBS), this vulcanized rubber 
possessed higher tensile strength, lower hardness, and consistent wet slip properties, which reduced the rolling resistance and heat generation of tread rubber.

Research on the safety of nitrosamines and low-toxicity accelerators is an imperative trend in the rubber industry. In addition, novel green accelerators should be used as alternatives to traditional accelerators to get unique physical and chemical properties.

Another prominent problem in the development of the rubber industry is the poor solubility of zinc oxide as an activator in the rubber matrix, which leads to uneven distribution of crosslinking bonds in the vulcanizates and reduces the mechanical properties of rubber products [6]. A large amount of zinc oxide failing to participate in the vulcanization reaction is more likely to be released into the environment through the abrasion of rubber products such as tires, causing serious environmental problems. Therefore, it is a significant challenge to reduce the amount of zinc oxide in the curing system without reducing the comprehensive performance of rubber products. Heideman et al. investigated the effect of zinc oxide at different stages of sulfur vulcanization though extensive experimental demonstrations [7]. It is possible to reduce the quantity of zinc oxide used in rubber formulations by 3-5 phr and still obtain acceptable properties, which provides a theoretical basis for this experiment.

General studies believe that rare-earth amino acid complexes have biomedical advantages as bactericidal and antiinflammatory; rare earth is a low toxicity substance, the same as iron. The rational application of rare earths is harmless to humans and has no pollution to the environment [8-11]. Lanthanum cerium cysteine (LC-Cys), a novel and nitrosamine safety additive, has both accelerating and activating effects. Simultaneously, by introducing rare-earth ions, the cure characteristics of the vulcanizates can be improved and the amount of zinc oxide in the curing system can be reduced. LC-Cys has no secondary amine structure, which can effectively eliminate the threat to nitrosamines. Moreover, while ensuring the mechanical properties of the vulcanizates, LC-Cys is still able to guarantee processing safety and replace the inefficient zinc oxide fraction.

\section{Experimental}

2.1. Materials. Natural rubber (NR), RSS3, was purchased from Shanghai Fuyou International Trade Co., Ltd.; cerium chloride $\left(\mathrm{CeCl}_{3} \cdot 7 \mathrm{H}_{2} \mathrm{O}\right)$, lanthanum chloride $\left(\mathrm{LaCl}_{3} \cdot 7 \mathrm{H}_{2} \mathrm{O}\right)$, L-Cysteine, zinc oxide ( $\mathrm{ZnO})$, stearic acid (St.A.), sulfur, accelerator 2-mercaptobenzothiazole (MBT), and accelerator 2,2' -dibenzothiazoledisulfde (MBTS) were all analytically pure, obtained from Shanghai Aladdin Biochemical Technology Co., Ltd.; and hydrochloric acid ( $\mathrm{HCl})$, anhydrous ethanol, and n-butanol were all commercially available.

2.2. Synthesis of LC-Cys. The synthesis procedure of preparing LC-Cys is given below. First, a small amount of $\mathrm{HCl}$ was dissolved in approximately $100 \mathrm{~mL}$ deionized water, followed by dissolution of L-Cysteine $(6.0 \mathrm{~g})$. $\mathrm{HCl}$ was added to prevent the oxidation of L-Cysteine in a neutral solution.
TABLE 1: Formulation of NR composites with different amounts of LC-Cys (phr).

\begin{tabular}{lccccc}
\hline Ingredient & 1 & 2 & 3 & 4 & 5 \\
\hline $\mathrm{NR}$ & 100 & 100 & 100 & 100 & 100 \\
ZnO & 5 & 5 & 5 & 4 & 3 \\
St.A. & 4 & 4 & 4 & 4 & 4 \\
Sulfur & 2.3 & 2.3 & 2.3 & 2.3 & 2.3 \\
MBT & 0.3 & 0.3 & 0.3 & 0.3 & 0.3 \\
MBTS & 1.6 & 1.6 & 1.6 & 1.6 & 1.6 \\
LC-Cys & 0 & 1 & 2 & 1 & 2 \\
\hline
\end{tabular}

Then, a mixture of $\mathrm{CeCl}_{3} \cdot 7 \mathrm{H}_{2} \mathrm{O}(4.0 \mathrm{~g})$ and $\mathrm{LaCl}_{3} \cdot 7 \mathrm{H}_{2} \mathrm{O}$ $(2.2 \mathrm{~g})$ was transferred into L-Cysteine solution. Meanwhile, the solution was heated to $60^{\circ} \mathrm{C}$ for $6 \mathrm{~h}$ under constant stirring. Afterwards, the resulting solution was concentrated until a crystal film appeared. After cooling, a mixture of anhydrous ethanol and n-butanol was added to precipitate the crude LC-Cys product out. Subsequently, the crude product was filtered by the above mixture of anhydrous ethanol and n-butanol. Ultimately, the purified product LC-Cys was dried thoroughly in an oven at $40^{\circ} \mathrm{C}$.

2.3. Preparation of NR Composites. NR composites were prepared according to the two-step procedure. First, natural rubber composites were mixed on a laboratory two-roll mill (Dongguan Houjie Kaiyan Machinery Equipment Factory, China) at $70^{\circ} \mathrm{C}$ according to ASTM D 3182. Specifically, NR was plasticized by passing through the roller five times, and then, zinc oxide, stearic acid, accelerator (MBT, MBTS, LC-Cys), and sulfur were added in turn. Then, cure characteristics of the vulcanizates were obtained by a MDR 2000 rheometer (Shanghai Dejie Equipment Co., Ltd., China) at $150^{\circ} \mathrm{C} \times 1 \mathrm{~h}$.

The NR composite formulation is shown in Table 1.

\subsection{Characterization}

2.4.1. Fourier Transform Infrared Spectroscopy (FT-IR). FTIR spectra of L-Cysteine and LC-Cys were determined by a frontier Fourier transform infrared spectrometer (PerkinElmer Co., Ltd., America) with the $\mathrm{KBr}$ tablet method. The scanning wave number was $4000 \mathrm{~cm}^{-1}$ to $400 \mathrm{~cm}^{-1}$; the resolution was $4 \mathrm{~cm}^{-1}$.

\subsubsection{Thermogravimetric Analysis-Differential Scanning} Calorimetry (TGA-DSC). The complex was tested by a TGA/DSC3+ synchronous thermal analyzer (Mettler Toledo International Trading Co., Ltd., Switzerland). Each sample weighing about $10-20 \mathrm{mg}$ was heated from room temperature to $1000^{\circ} \mathrm{C}$ at the heating rate $\left(10^{\circ} \mathrm{C} / \mathrm{min}\right)$ under an air flow of $20 \mathrm{~mL} / \mathrm{min}$.

2.4.3. Elemental Analysis. The content of C, H, N, and S in the complex was recorded by a Vario EL cube elemental 


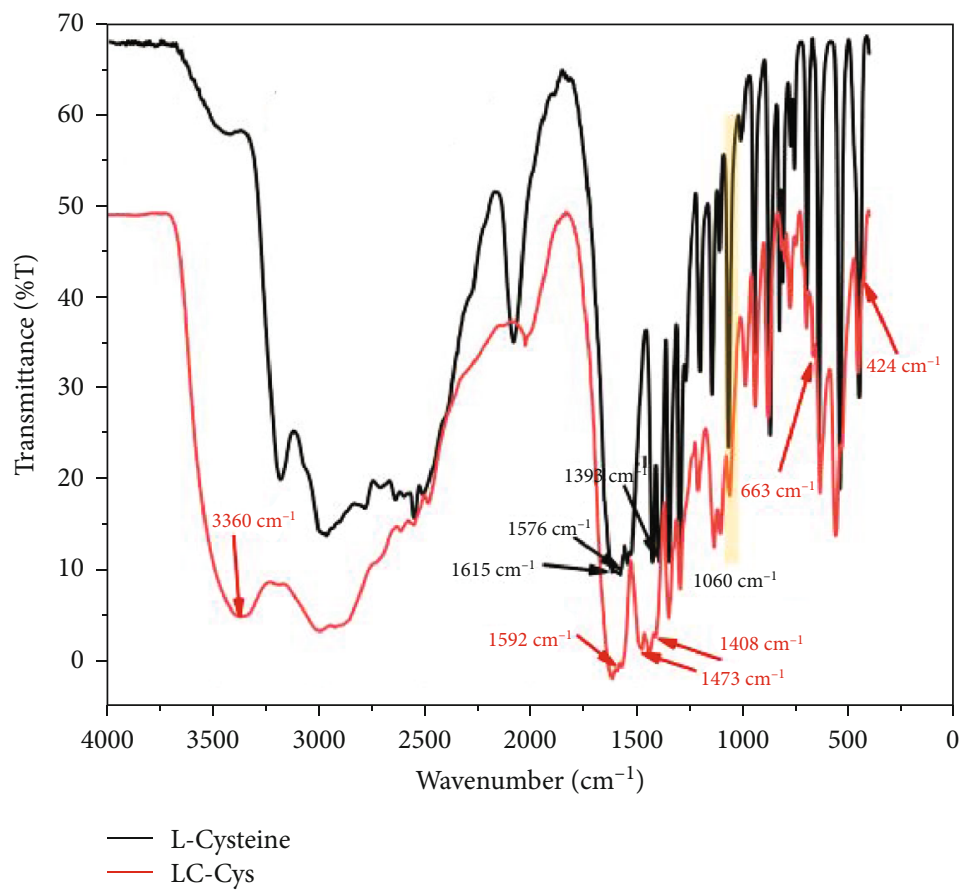

(a)

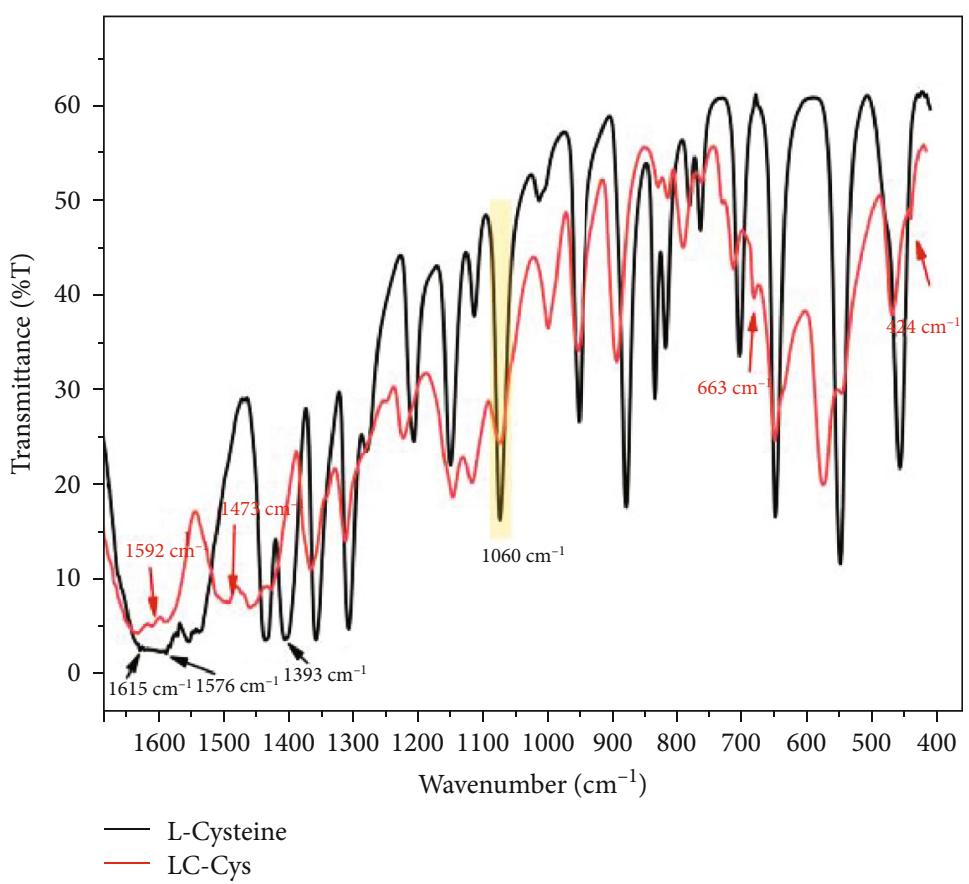

(b)

Figure 1: (a) FT-IR of L-Cysteine and LC-Cys; (b) the range of $400-1700 \mathrm{~cm}^{-1}$ in FT-IR.

analyzer (Elementar Analysensysteme GmBh, German) according to the ISO 29541-2010 standard.

2.4.4. Inductively Coupled Plasma Optical Emission Spectrometry (ICP-OES). The content of Ce and $\mathrm{La}$ in the complex was tested by a 5110 inductively coupled plasma optical emission spectrometer (Agilent Technology Co., Ltd., America) according to the ASTM UOP714-2007 standard.
2.4.5. Crosslink Density Test. The vulcanizates were subjected to an equilibrium swelling experiment according to the HG/ $\mathrm{T}$ 3870-2008 standard [12]. The volume fraction (Vr) of vulcanizates was calculated according to the method reported by Ellis and Welding [13].

$$
\mathrm{Vr}=\frac{m_{1} / \rho_{1}}{\left[m_{1} / \rho_{1}+\left(m_{3}-m_{1}\right) / \rho_{2}\right]},
$$




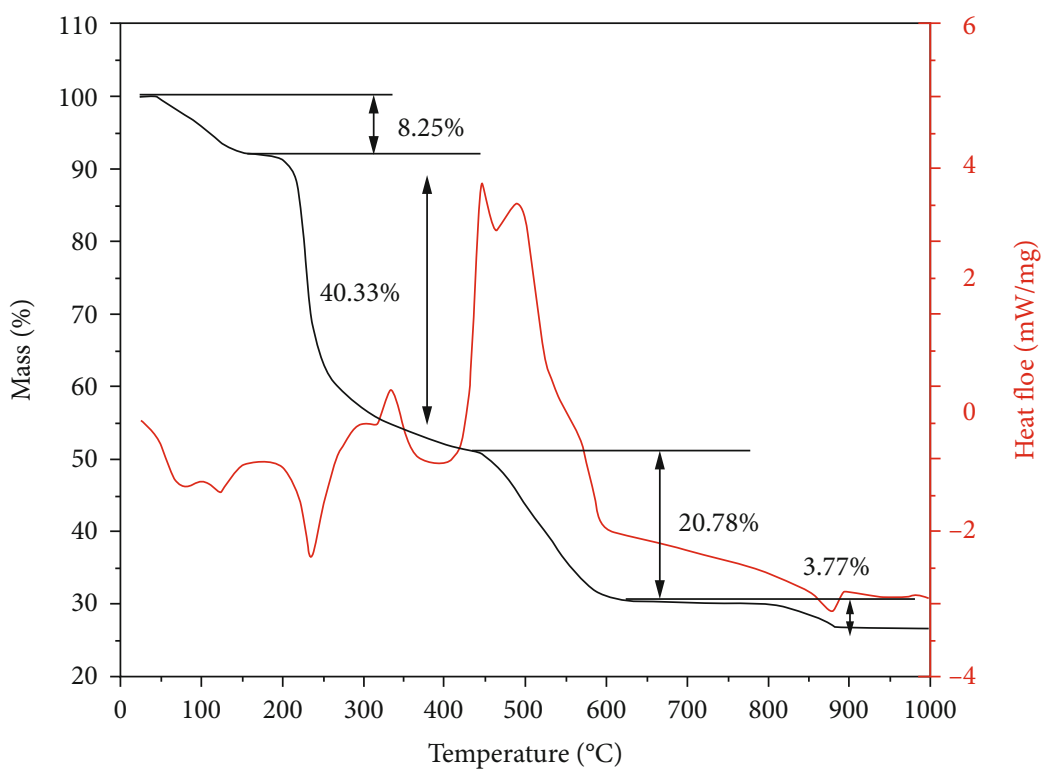

FIgure 2: TGA-DSC curves of LC-Cys.

where $m_{1}$ is the deswelling weight of the sample, $m_{3}$ is the swelling weight of the sample, and $\rho_{1}$ and $\rho_{2}$ are the densities of vulcanized rubber and benzene, respectively.

The crosslink density of NR vulcanizates without fillers was investigated according to Flory-Rehner and FloryHuggins equation [14].

$$
V_{\varepsilon}=-\frac{\ln (1-\mathrm{Vr})+\mathrm{Vr}+\chi \mathrm{Vr}^{2}}{V_{1}\left(\mathrm{Vr}^{1 / 3}-1 / 2 \mathrm{Vr}\right)}
$$

where $V_{1}$ is the molar volume of benzene $\left(89.4 \mathrm{~cm}^{3} /\right.$ $\mathrm{mol}), \mathrm{Vr}$ is the volume fraction of vulcanized rubber during swelling, and $\chi$ is the interaction parameter; for the NRbenzene system, the value of $\chi$ can be used as a constant (0.437) [15].

2.4.6. Mechanical Property Measurement. The mechanical properties were measured on a E43.504 electronic universal testing machine (Mettes Industrial Systems Co., Ltd., China) at a crosshead speed of $500 \mathrm{~mm} / \mathrm{min}$ according to ISO 37:2017. Five dumbbell samples prepared by the NR composites were examined, and the average value of the experiment was taken as the result. The Shore A hardness was measured for disc-shaped samples of NR composites by an LX-A rubber hardness tester (Xinzhenwei Testing Machine Co., Ltd., China) according to ISO 868-2003.

The dynamic mechanical properties of the vulcanizates were measured by dynamic thermomechanical analysis (DMA) using a DMA 850 dynamic thermal mechanical analyzer (TA Instruments, America). The samples were prepared in the shape of a rectangular test spline with a length of $60 \mathrm{~mm}$, a width of $12 \mathrm{~mm}$, and a thickness of $2 \mathrm{~mm}$. The test frequency was $1 \mathrm{~Hz}$, dynamic strain amplitude was $20 \mu \mathrm{m}$, and static preload was $0.01 \mathrm{~N}$. The spline was cooled at $-85^{\circ} \mathrm{C}$ for $10 \mathrm{~min}$ and then heated to $60^{\circ} \mathrm{C}$ at a heating rate of $3^{\circ} \mathrm{C} / \mathrm{min}$.
TABLE 2: ICP and elemental analysis of the complex.

\begin{tabular}{lcc}
\hline Element & Test value (\%) & Theoretical value (\%) \\
\hline $\mathrm{C}$ & 16.14 & 16.36 \\
$\mathrm{H}$ & 3.85 & 3.66 \\
$\mathrm{~N}$ & 6.14 & 6.36 \\
$\mathrm{~S}$ & 14.54 & 14.55 \\
$\mathrm{Ce}$ & 14.48 & 14.43 \\
$\mathrm{La}$ & 8.01 & 7.77 \\
\hline
\end{tabular}

2.4.7. Thermooxidative Aging Measurement. According to Nellen and Sellers, four days of aging for NR in an oven at $70^{\circ} \mathrm{C}$ was equivalent to one year of natural aging [16]. The thermooxidative aging of the NR composites was conducted at $70^{\circ} \mathrm{C}$. The dumbbell-shaped NR composites were suspended in a DZF-6090 oven (Shanghai Yiheng Technology Co., Ltd., China) and were removed from the oven every $24 \mathrm{~h}$ for $96 \mathrm{~h}$.

2.4.8. Standard Deviation Analysis. The error analysis was performed by the Standard Deviation (SD).

$$
\mathrm{SD}=\frac{\sqrt{\sum_{i=1}^{n}\left(x_{i}-\bar{x}\right)^{2}}}{n-1},
$$

where $n$ is the number of data, $x_{i}$ are the experimental values, and $\bar{x}$ is the average of the experimental values.

\section{Results and Discussion}

\subsection{Characterization of LC-Cys}

3.1.1. FT-IR Analysis. The FT-IR spectra of L-Cysteine and LC-Cys is given in Figure 1. The stretching vibration peak of the C-N group at $1060 \mathrm{~cm}^{-1}$ is not varied, indicating that 


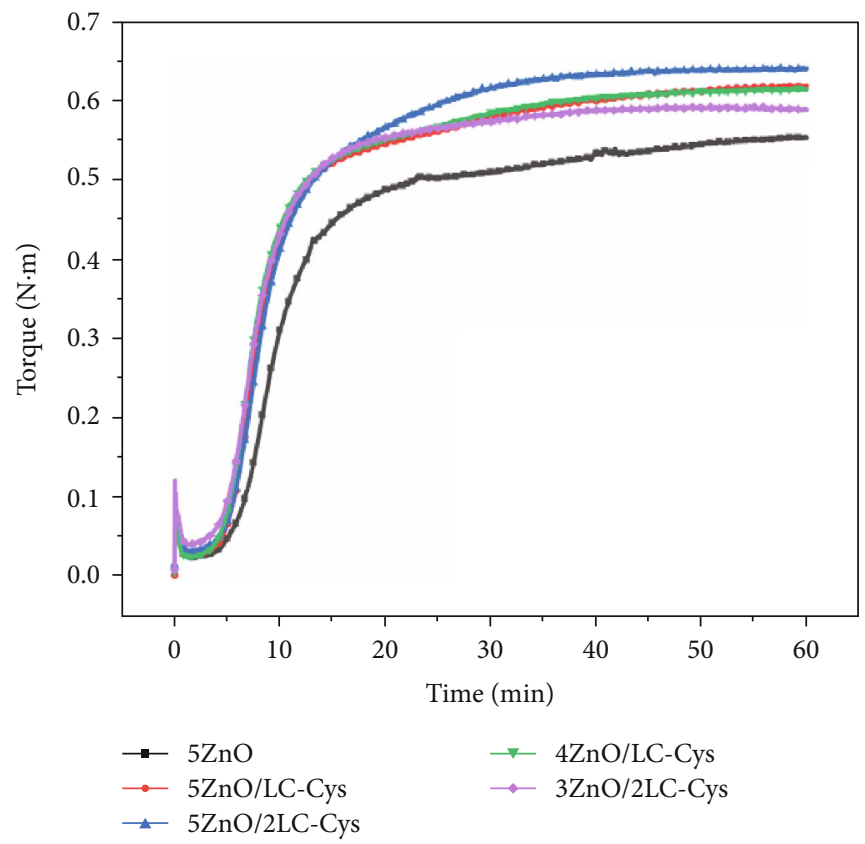

Figure 3: Cure curves of the vulcanizates with different LC-Cys/ZnO additions.

the $\mathrm{N}$ atom in the ligand fails to participate in the coordination of rare-earth ions. Compared with the - $\mathrm{COO}^{-}$symmetrical and antisymmetrical stretching peaks at $1393 \mathrm{~cm}^{-1}$ and $1576 \mathrm{~cm}^{-1}$ for L-Cysteine, respectively, the -COO$^{-}$symmetrical and antisymmetrical stretching peaks shift to $1408 \mathrm{~cm}^{-1}$ and $1592 \mathrm{~cm}^{-1}$ for LC-Cys, respectively. This blue shift phenomenon can be explained by the coordination of rare-earth ions [17]. The FT-IR spectrum of O-La $\left(663 \mathrm{~cm}^{-1}\right)$ and O-Ce $\left(424 \mathrm{~cm}^{-1}\right)$ for the synthesized complexes also demonstrates the successful preparation of LC-Cys [18]. Also, $3360 \mathrm{~cm}^{-1}$ is the absorption peak of crystal water, indicating that LCCys contains crystal water [19]. The bending vibration peak of $-\mathrm{NH}_{2}$ at $1615 \mathrm{~cm}^{-1}$ disappears in LC-Cys; new peaks $\left(-\mathrm{NH}_{3}{ }^{+}\right)$appear at $1473 \mathrm{~cm}^{-1}$, indicating that the amino group is protonated [20].

3.1.2. TGA-DSC Analysis. LC-Cys is measured by TGA-DSC shown in Figure 2. The decomposition of the rare-earth complex is divided into four stages. In the first stage, the complex has a weight loss of $8.25 \%$ before $190^{\circ} \mathrm{C}$, and an absorption peak appears on the corresponding DSC curve, which is due to the loss of the crystal water. Therefore, the conclusion that can be drawn from further analysis is that the complex contains three crystal waters. The second stage is $190^{\circ} \mathrm{C} \sim 440^{\circ} \mathrm{C}$, with a weight loss of $40.33 \%$. There is a heat absorption peak on the DSC curve corresponding to the heat absorption decomposition of the amino and carboxyl group [21] for the initial degradation temperature $\left(190^{\circ} \mathrm{C}\right)$, compared to general vulcanization temperature, suggesting that the thermal stability of LC-Cys fulfills the requirements of the vulcanization process [22]. The third stage is $440^{\circ} \mathrm{C} \sim 600^{\circ} \mathrm{C}$ with a weight loss of $20.78 \%$. There is an exothermic peak on the DSC curve, which corresponds to the exothermic decomposition of the residue in the complex.
The fourth stage is $600^{\circ} \mathrm{C} \sim 890^{\circ} \mathrm{C}$, with a weight loss of $3.77 \%$. A heat absorption peak appears on the DSC curve, which is mainly due to the transformation from rare-earth complexes to rare-earth oxides $\left(\mathrm{La}_{2} \mathrm{O}_{3}\right.$ and $\left.\mathrm{CeO}_{2}\right)$.

3.1.3. ICP-OES and Element Analysis. The $\mathrm{C}, \mathrm{H}, \mathrm{N}$, and $\mathrm{S}$ content measured by an elemental analyzer and the rareearth (La and $\mathrm{Ce}$ ) content tested by ICP-OES are listed in Table 2. The contents of C, H, N, S, La, and Ce in the complex are almost identical to those in the literature [18], and the molecular formula of the complex is determined as $\mathrm{La}_{0.35} \mathrm{Ce}_{0.65}(\mathrm{Cys})_{3} \mathrm{Cl}_{3} \cdot 3 \mathrm{H}_{2} \mathrm{O}$.

\subsection{Effect of LC-Cys/ZnO Additions on the Cure Characteristics of the Vulcanizates}

3.2.1. Cure Curve and Cure Characteristics. The effect of LC$\mathrm{Cys} / \mathrm{ZnO}$ addition on cure curves of the rubber composites is given in Figure 3. The cure characteristics of the vulcanized rubber are summarized in Table 3.

It can be seen that the vulcanization process of NR composites is significantly facilitated by the introduction of LCCys. The minimum torque $\left(M_{\mathrm{L}}\right)$ corresponds to the viscosity of the vulcanized rubber before vulcanization, which characterizes the molecular weight and reflects the processing properties of the rubber-mainly the flowability of rubber. Generally, the conclusion is drawn that the number of accelerators and activators has no influence on the viscosity of uncured NR composites [23]. Similarly, LC-Cys and zinc oxide additions have no influence on the viscosity of uncured NR composites.

The crosslink density is characterized by torque based on the fact that it is proportional to the stiffness of the vulcanized rubber. After adding LC-Cys, an increase in $M_{\mathrm{H}}$ and 
TABLE 3: Cure characteristics of natural rubber with LC-Cys/ZnO additions.

\begin{tabular}{lcccrc}
\hline Compound & $M_{\mathrm{H}}(\mathrm{N} \cdot \mathrm{m})$ & $M_{\mathrm{L}}(\mathrm{N} \cdot \mathrm{m})$ & $\Delta M(\mathrm{~N} \cdot \mathrm{m})$ & $t_{\mathrm{s} 2}(\mathrm{~min})$ & $t_{90}(\mathrm{~min})$ \\
\hline $5 \mathrm{ZnO}$ & $0.554 \pm 0.012$ & $0.022 \pm 0.004$ & $0.532 \pm 0.008$ & $8.60 \pm 0.37$ & $22.88 \pm 0.87$ \\
$5 \mathrm{ZnO} /$ LC-Cys & $0.631 \pm 0.018$ & $0.025 \pm 0.003$ & $0.606 \pm 0.015$ & $7.17 \pm 0.24$ & $15.52 \pm 1.04$ \\
$5 \mathrm{ZnO} / 2 \mathrm{LC}-\mathrm{Cys}$ & $0.641 \pm 0.007$ & $0.025 \pm 0.004$ & $0.627 \pm 0.003$ & $7.37 \pm 0.18$ & $20.10 \pm 1.23$ \\
$4 \mathrm{ZnO} /$ LC-Cys & $0.616 \pm 0.010$ & $0.023 \pm 0.002$ & $0.588 \pm 0.008$ & $8.60 \pm 0.22$ & $22.83 \pm 0.63$ \\
$3 \mathrm{ZnO} / 2 \mathrm{LC}-$ Cys & $0.593 \pm 0.015$ & $0.026 \pm 0.007$ & $0.554 \pm 0.012$ & $6.92 \pm 0.31$ & $16.30 \pm 0.58$ \\
\hline
\end{tabular}

$M_{\mathrm{H}}$ : maximum torque; $M_{\mathrm{L}}$ : minimum torque; $\Delta M: M_{\mathrm{H}}-M_{\mathrm{L}} ; t_{\mathrm{s} 2}$ : scorch time; $t_{90}$ : optimum curing time.

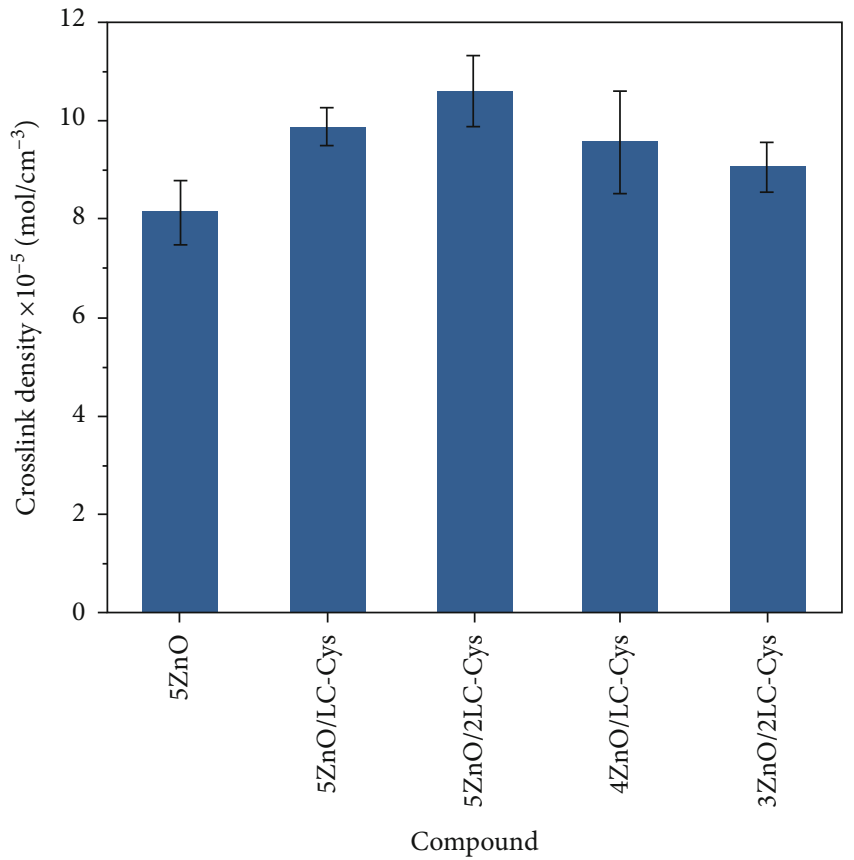

Figure 4: The effect of LC-Cys/ZnO additions on crosslink density.

TABLE 4: Effect of LC-Cys/ZnO additions on the mechanical properties.

\begin{tabular}{|c|c|c|c|c|c|}
\hline Compound & EB (\%) & TS (MPa) & M100 (MPa) & M300 (MPa) & $\mathrm{H}(\mathrm{ShA})$ \\
\hline $5 \mathrm{ZnO}$ & $863 \pm 35$ & $14.42 \pm 0.68$ & $1.07 \pm 0.09$ & $3.06 \pm 0.13$ & $25 \pm 0.82$ \\
\hline $5 \mathrm{ZnO} / \mathrm{LC}-\mathrm{Cys}$ & $823 \pm 44$ & $16.51 \pm 0.96$ & $1.35 \pm 0.05$ & $3.35 \pm 0.15$ & $28 \pm 1.24$ \\
\hline $5 \mathrm{ZnO} / 2 \mathrm{LC}-\mathrm{Cys}$ & $804 \pm 27$ & $18.03 \pm 0.36$ & $1.52 \pm 0.11$ & $3.67 \pm 0.08$ & $31 \pm 0.56$ \\
\hline 4ZnO/LC-Cys & $766 \pm 33$ & $16.23 \pm 0.59$ & $1.37 \pm 0.06$ & $3.52 \pm 0.15$ & $26 \pm 0.93$ \\
\hline 3ZnO/2LC-Cys & $728 \pm 51$ & $15.28 \pm 0.87$ & $1.22 \pm 0.04$ & $3.18 \pm 0.21$ & $24 \pm 0.78$ \\
\hline
\end{tabular}

EB: elongation at break, TS: tensile strength, M100: modulus at a relative elongation of 100\%, M300: modulus at a relative elongation of 300\%, H: Hardness.

$\Delta M$ is immediately observed, and then, the values of $M_{\mathrm{H}}$ and $\Delta M$ increased with increasing LC-Cys concentration, which indicates that the stiffness and crosslink density of the vulcanizates are enhanced. On the other hand, it seems that $\mathrm{ZnO}$ levels can be reduced to a minimum of about 2 phr without serious detrimental effects on properties [24]. A small reduction in modulus can be compensated by a slight increase in levels of the accelerators. This is consistent with the experimental phenomenon reflected; $4 \mathrm{ZnO} / \mathrm{LC}-\mathrm{Cys}$ and $3 \mathrm{ZnO} / 2 \mathrm{LC}-\mathrm{Cys}$ have a higher modulus of the vulcanizates compared with $5 \mathrm{ZnO}$.

As is commonly known, MBT and MBTS as conventional vulcanization accelerators provide moderate cure rates in the vulcanization processing. The $t_{90}$ decreases from $22.88 \mathrm{~min}$ for the NR composites without LC-Cys to $15.52 \mathrm{~min}$ for the composites with $5 \mathrm{ZnO} / \mathrm{LC}$-Cys. Therefore, LC-Cys exhibits excellent vulcanization promotion for natural rubber. This is due to the accelerated behavior of the $-\mathrm{SH}$ 


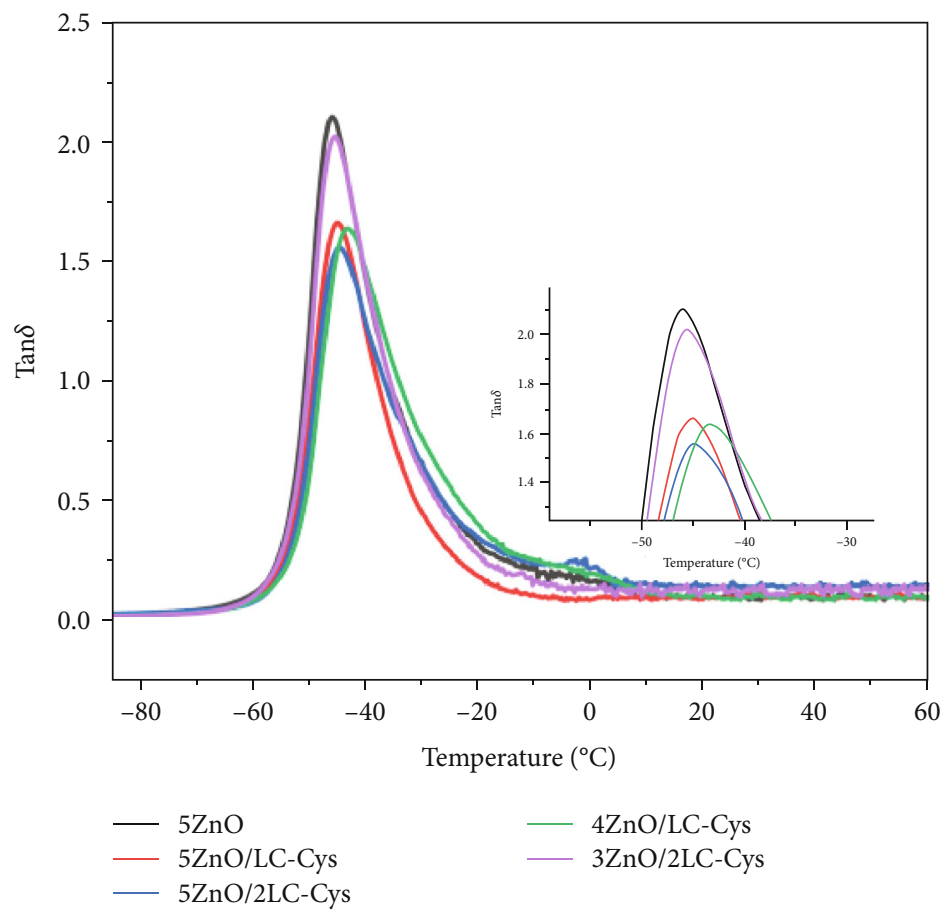

(a)

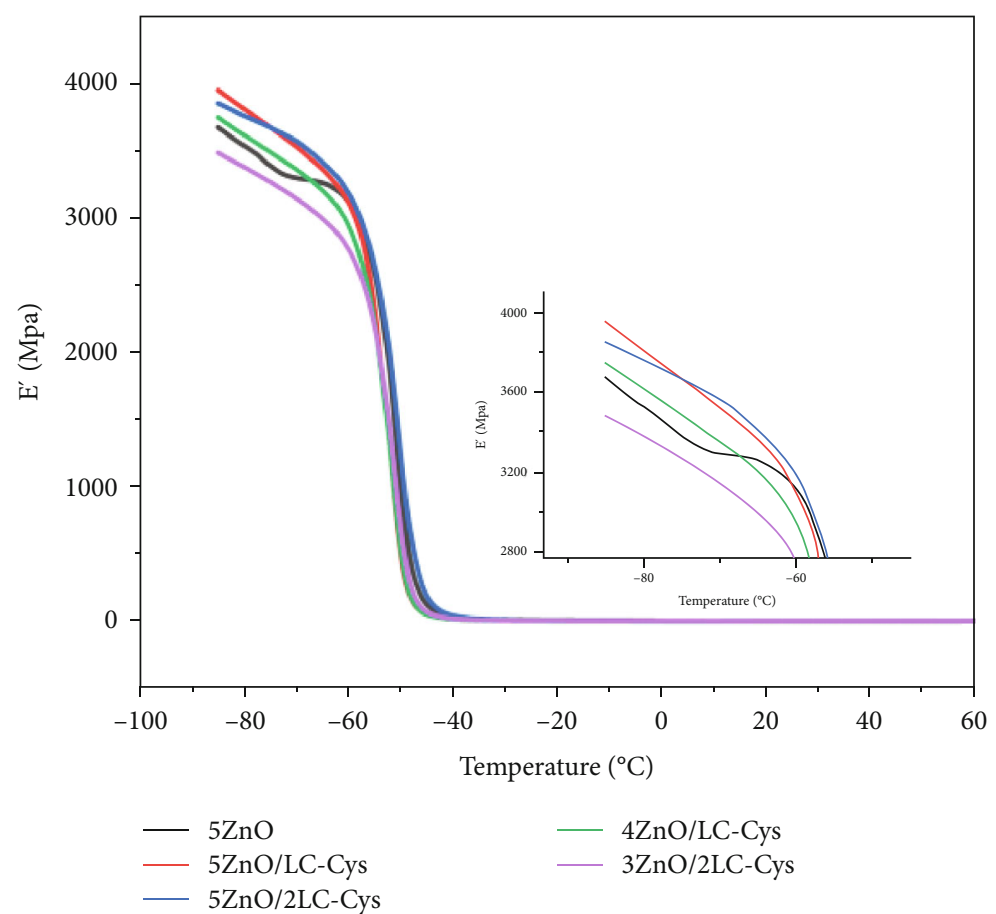

(b)

Figure 5: (a) Mechanical loss factor $\left(\tan \delta\right.$ ) and (b) storage modulus $\left(E^{\prime}\right)$ versus the temperature of the vulcanizates.

group and amino group, which raises the reactivity of the crosslink precursors and enhances the nucleation state of the reactive groups of the natural rubber molecular chain as well as the activity of other accelerators [25]. Compared with cysteine (molecular weight $=121)$, which has only one -SH group and amino group to accelerate vulcanization, accelerated behavior of the same mass of LC-Cys (molecular weight $=659)$ is more pronounced .

As expected, NR composites containing LC-Cys exhibit considerably acceptable scorch time. Although, the optimum curing time of the vulcanizates with LC-Cys is drastically reduced, compared with that of the vulcanizates containing 
TABle 5: Glass transition temperature $\left(T_{\mathrm{g}}\right)$ and mechanical loss factor $(\tan \delta)$ of the vulcanizates.

\begin{tabular}{lcccc}
\hline Compound & $T_{\mathrm{g}}\left({ }^{\circ} \mathrm{C}\right)$ & $\tan \delta_{(\mathrm{Tg})}(-)$ & $\tan \delta_{(25)}(-)$ & $\tan \delta_{(60)}(-)$ \\
\hline $5 \mathrm{ZnO}$ & $-45.7 \pm 1.4$ & $2.21 \pm 0.14$ & $0.13 \pm 0.02$ & $0.11 \pm 0.03$ \\
$5 \mathrm{ZnO} /$ LC-Cys & $-44.4 \pm 0.8$ & $1.71 \pm 0.21$ & $0.08 \pm 0.02$ & $0.08 \pm 0.02$ \\
$5 \mathrm{ZnO} / 2 \mathrm{LC}-$ Cys & $-45.8 \pm 1.3$ & $1.59 \pm 0.09$ & $0.15 \pm 0.03$ & $0.11 \pm 0.02$ \\
$4 \mathrm{ZnO} /$ LC-Cys & $-44.5 \pm 0.6$ & $1.61 \pm 0.13$ & $0.08 \pm 0.01$ & $0.06 \pm 0.01$ \\
$3 \mathrm{ZnO} / 2 \mathrm{LC}-$ Cys & $-45.9 \pm 1.7$ & $1.87 \pm 0.15$ & $0.14 \pm 0.02$ & $0.12 \pm 0.02$ \\
\hline
\end{tabular}

$T_{\mathrm{g}}$ : glass-transition temperature; $\tan \delta_{(\mathrm{Tg})}, \tan \delta_{(25)}$, and $\tan \delta_{(60)}$ : loss factors at $T_{\mathrm{g}}, 25^{\circ} \mathrm{C}$, and $60^{\circ} \mathrm{C}$, respectively.

TABLE 6: Storage modulus $(E)$ of the vulcanizates.

\begin{tabular}{llll}
\hline Compound & $E_{(-85)}^{\prime}(\mathrm{MPa})$ & $E_{(25)}^{\prime}(\mathrm{MPa})$ & $E_{(60)}^{\prime}(\mathrm{MPa})$ \\
\hline $5 \mathrm{ZnO}$ & $3687 \pm 87$ & $2.46 \pm 0.11$ & $2.37 \pm 0.16$ \\
$5 \mathrm{ZnO} /$ LC-Cys & $3895 \pm 123$ & $2.35 \pm 0.07$ & $2.26 \pm 0.13$ \\
$5 \mathrm{ZnO} / 2 \mathrm{LC}-$ Cys & $3912 \pm 116$ & $3.26 \pm 0.23$ & $3.18 \pm 0.09$ \\
$4 \mathrm{ZnO} /$ LC-Cys & $3766 \pm 82$ & $2.24 \pm 0.15$ & $2.17 \pm 0.14$ \\
$3 \mathrm{ZnO} / 2 \mathrm{LC}-\mathrm{Cys}$ & $3564 \pm 67$ & $3.23 \pm 0.05$ & $3.12 \pm 0.11$ \\
\hline
\end{tabular}

${\overline{E^{\prime}}}_{(-85)}, E_{(25)}^{\prime}$, and $E_{(60)}^{\prime}$ : storage moduli at $-85^{\circ} \mathrm{C}, 25^{\circ} \mathrm{C}$, and $60^{\circ} \mathrm{C}$, respectively.

$5 \mathrm{ZnO}$, the scorch time of NR composites with LC-Cys is not significantly shortened. This is most likely due to the fact that rare-earth metals increase the critical activation temperature of the accelerator, prolong the thermal process of the composite formation, and reduce the hysteresis loss of the vulcanizates [26].

3.2.2. Crosslink Density. The data in Figure 4 is analyzed to investigate the effect of LC-Cys/ZnO additions on crosslink density. Distinctly, the vulcanizates cured with LC-Cys exhibit higher crosslink density compared to those without LC-Cys. The number of crosslinks in the NR network is subjected to the type or number of accelerators, activators, and fillers used. The crosslink density of the vulcanizates containing LC-Cys tends to decrease because of the reduction of $\mathrm{ZnO}$. However, despite the $40 \%$ reduction in $\mathrm{ZnO}$ content in the NR composites, the vulcanizates maintain a high level of crosslink, which is a considerably acceptable range. This may be due to the help of the -SH group, where the molecule can graft in several rubber molecules at the same time, thus strengthening the crosslinking between molecules [27].

\subsection{Effect of LC-Cys/ZnO Additions on the Mechanical Properties and Dynamic Mechanical Properties}

3.3.1. Mechanical Properties. It is well known that the application of NR products is closely related to their mechanical properties. The mechanical properties of the vulcanizates with different LC-Cys/ZnO additions are displayed in Table 4.

The trends of TS, M100, M300, and crosslink density of the NR composites are relatively similar. Thus, the vulcanizates prepared with $5 \mathrm{ZnO} / 2 \mathrm{LC}$-Cys exhibit the highest tensile strength. Moreover, the tensile strength of vulcanized rubber with LC-Cys and lower $40 \% \mathrm{ZnO}$ content is higher than that of vulcanized rubber containing $5 \mathrm{ZnO}$. This results from the considerable increase in crosslink density of the vulcanizates.

As expected, elongation at break of the vulcanizates prepared with LC-Cys performs lower values in comparison with the vulcanizates without LC-Cys due to the increase in crosslink density and reduced the mobility of polymer chains [5].

It terms of the hardness of vulcanizates, LC-Cys increases the hardness of the vulcanizates containing $5 \mathrm{phr}$ $\mathrm{ZnO}$. This results from the increase in crosslink density of the vulcanizates compared with that of NR composites without LC-Cys.

3.3.2. Dynamic Mechanical Properties. In addition to the mechanical properties under static conditions, dynamic mechanical properties play numerous roles in the technical application of NR products. The effect of the LC-Cys/ZnO additions on mechanical loss factor $(\tan \delta)$ and storage modulus $\left(E^{\prime}\right)$ is shown in Figures $5(\mathrm{a})$ and 5(b), respectively, and therefore, the data are collected in Tables 5 and 6 , respectively.

The peak of the $\tan \delta$ curve versus temperature is considered as the transition process of the elastomer from the glassy to the rubbery elastic state, with the maximum peak corresponding to the temperature representing glasstransition temperature $\left(T_{\mathrm{g}}\right)$. The change in $T_{\mathrm{g}}$ of the vulcanizates is not evident, compared to the vulcanizates without LC-Cys. Therefore, it is concluded that the addition of LCCys has little influence on the $T_{\mathrm{g}}$ of the NR composites. Besides, the vulcanizates cured with LC-Cys have a lower $\tan \delta$ at $T_{\mathrm{g}}$ compared to NR composites without LC-Cys regardless of the $\mathrm{ZnO}$ additions used. The decrease in peak height of $\tan \delta$ is due to the increase in crosslink density 


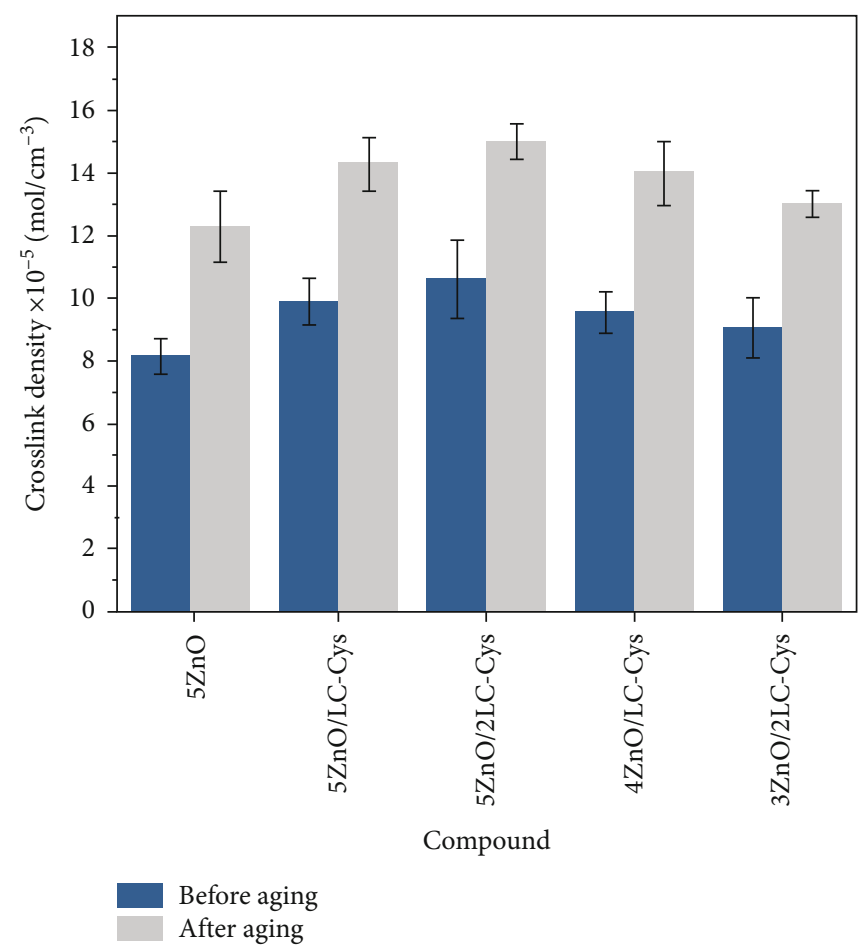

FIGURE 6: Crosslink density of the vulcanizates before and after aging.

of the vulcanizates. An elastic network with a high concentration of crosslinks reduces the free volume of polymer, restricts the mobility of the polymer chains, and reduces the elasticity of the vulcanizates. The mechanical loss factors of the NR vulcanizates in the temperature range of $25-60^{\circ} \mathrm{C}$ were comparable in terms of the experimental error. Due to small changes of $\tan \delta$ at $60^{\circ} \mathrm{C}$, it is found that $\tan \delta$ at $60^{\circ} \mathrm{C}$ of the vulcanizates containing LC-Cys exhibits similar or even smaller values after many experiments. This may reduce the rolling friction and hysteresis loss of NR composites. Besides, the vulcanizates exhibit stable dynamic mechanical properties in the rubbery elastic region, because the value of the mechanical loss factor does not fluctuate significantly with temperature after the elastomeric transition to the elastic state.

A general decreasing trend in the storage modulus $\left(E^{\prime}\right)$ with raising temperature is observed. In the glass-rubber transition process, the energy dissipation of the rubber chain movement causes a sharp drop [28]. Below the glass transition temperature, the vulcanizates containing LC-Cys exhibit higher storage modulus in the glassy state, except for those containing 3ZnO/2LC-Cys. The storage modulus increases with the addition of LC-Cys in the matrix, which may also be related to the enhanced effect of the limitation of the rubber chain segment motion. The $E$ ' curves presented in Figure 5(b) for the most of vulcanizates almost overlap in the rubber elastic region, whereas the $E^{\prime}$ values present in Table 5 in the range of $25-60^{\circ} \mathrm{C}$ are comparable, considering the measurement uncertainty. Above the glass transition temperature, the $E^{\prime}$ value of the NR composites containing $5 \mathrm{ZnO} / 2 \mathrm{LC}-\mathrm{Cys}$ is higher than other vulcanizates.
This further reflects that an increasing number of restricted rubber chains are formed as a result of crosslinking the diene with the thiol group.

3.4. Effect of LC-Cys/ZnO on Resistance of the NR Vulcanizates to Thermooxidative Aging. Thermooxidative aging of natural rubber is one of the most significant characteristics for evaluating its application for daily life and industrial manufacturing. The aging of the vulcanizates used in this experiment under thermal oxidative conditions is similar to that observed during the vulcanization process, due to the increase in crosslink density [24, 29].

The effect of thermooxidative aging on the crosslink density of NR elastomers is shown in Figure 6. The increase in crosslink density is recorded after being exposed to the conditions of thermooxidative aging. Elevated temperature increases the diffusion of oxygen in the rubber matrix and activates oxidation reactions, resulting in either a reduction in molecular weight due to chain scission or additional crosslinking [30].

The effect of thermooxidative aging on the elongation at break of the vulcanizates is shown in Figure 7(a). For the vulcanizates without LC-Cys, the elongation at break decreases rapidly after the aging process. However, for NR composites filled with LC-Cys, a smaller decrease in elongation at break after thermooxidative aging is observed. Consequently, the vulcanizates containing LC-Cys show superior aging resistance regardless of the $\mathrm{ZnO}$ additions.

Another result of the increase in crosslink density under the effect of thermooxidative aging is a significant reduction in tensile strength shown in Figure 7(b). It is commonly 


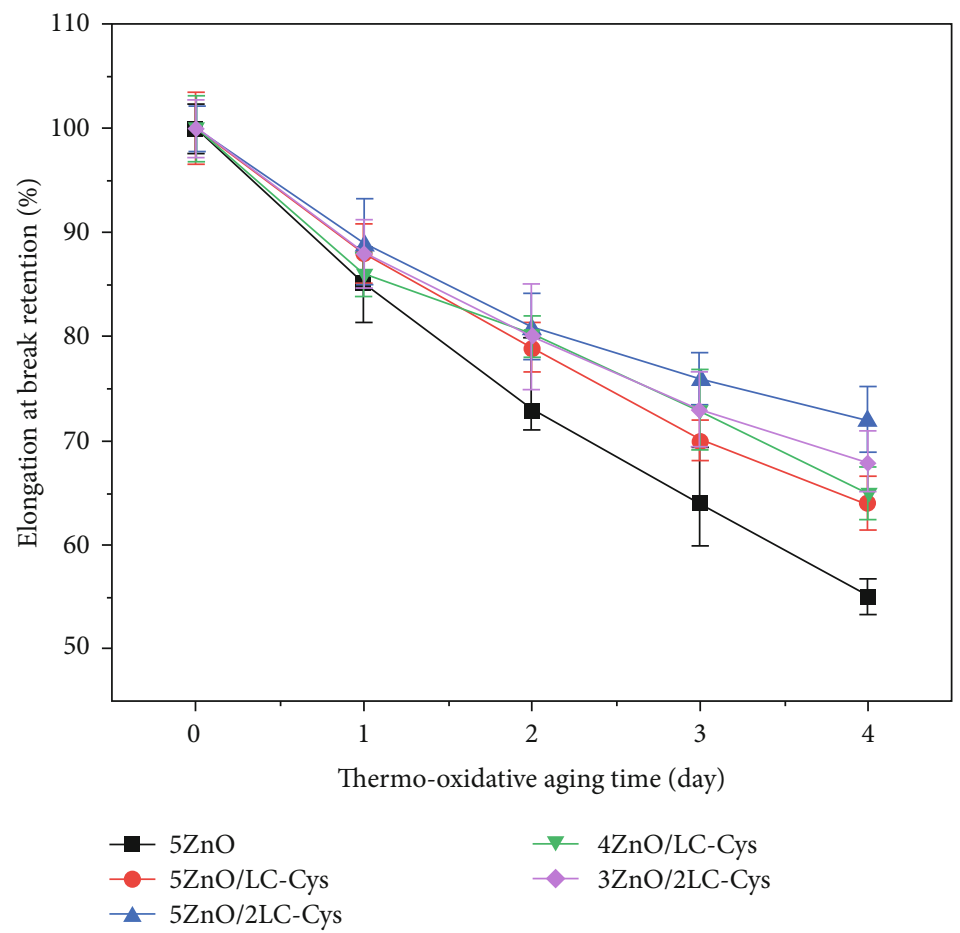

(a)

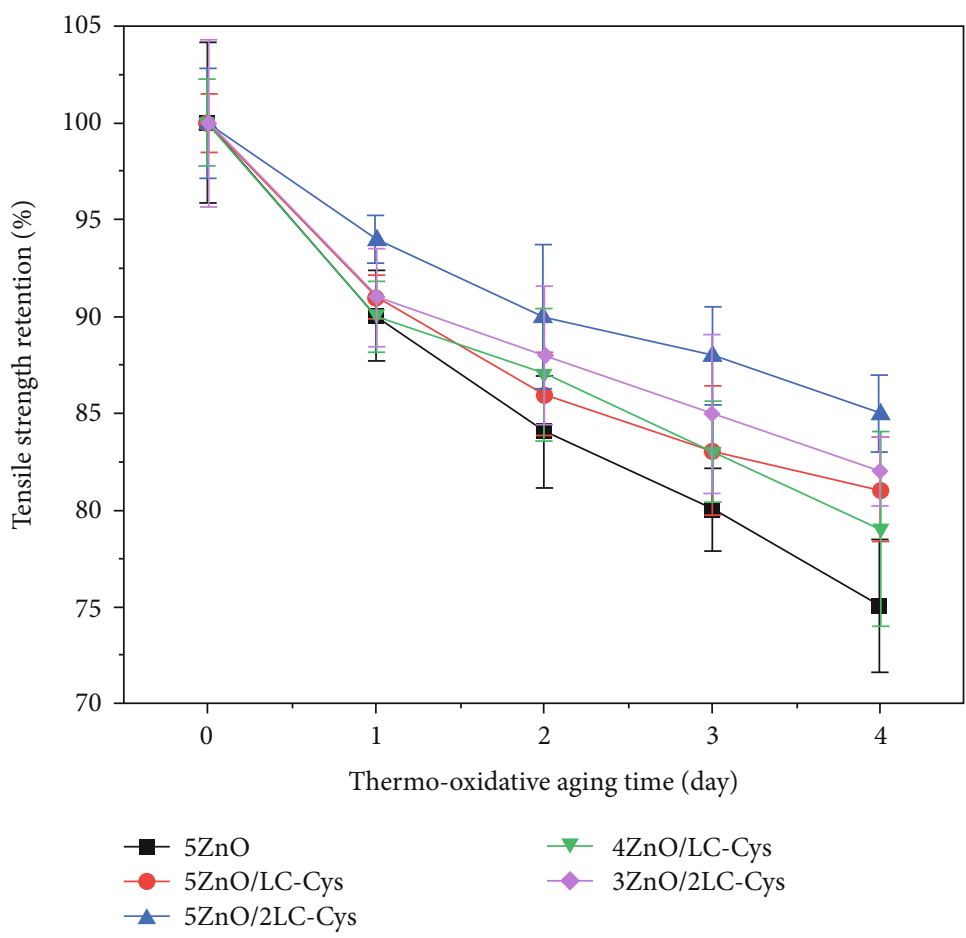

(b)

Figure 7: (a) Elongation at break retention and (b) tensile strength retention of the vulcanizates after different aging times.

known that tensile strength increases with increasing crosslink density up to a critical concentration of crosslinks in the polymer chain network. Further increase in the crosslink density results in the deterioration of the tensile strength as the vulcanizates become more brittle and susceptible to fracture under external stresses [31]. During thermooxidative aging, excessive primary fracture and modifications as well as crosslink recombination disrupt highly sterically regular structure of NR, which subsequently leads to a reduced tendency of composites to crystallize. This manifests itself mainly as a dramatic deterioration in tensile strength [32]. However, the vulcanizates containing LC-Cys show less 


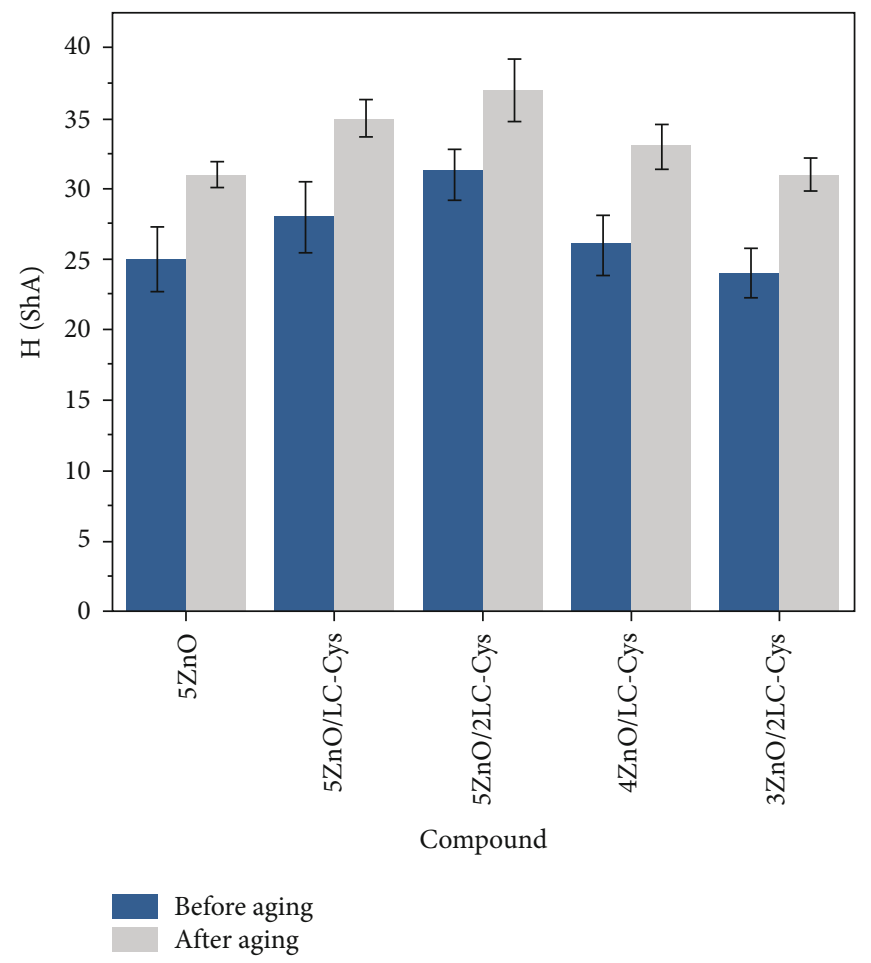

FIgURE 8: Hardness of the vulcanizates before and after aging.

change due to thermooxidative aging, compared with that of the vulcanizates without LC-Cys. This is due to a large number of empty orbital props of rare-earth elements with high blinding ability to free radicals, which terminates the chain reaction and effectively inhibits the continuation of autooxidation [33-36].

The effect of thermooxidative aging on the hardness of the NR composites is shown in Figure 8. The NR vulcanizates exhibit higher hardness after the thermooxidative aging process compared with samples without aging. This results from the increase in their crosslink density. LC-Cys seems to have no contribution on the hardness of the vulcanizates due to aging, compared with the vulcanizates without this ingredient.

\section{Conclusion}

A novel additive lanthanum cerium cysteine (LC-Cys) was prepared successfully and the molecular formula of the complex was determined as $\mathrm{La}_{0.35} \mathrm{Ce}_{0.65}(\mathrm{Cys})_{3} \mathrm{Cl}_{3} \cdot 3 \mathrm{H}_{2} \mathrm{O}$.

The optimum curing time of the NR composites containing LC-Cys is significantly shorter than that of the composites without LC-Cys, despite the fact that the $\mathrm{ZnO}$ addition is $40 \%$ lower than the latter. In addition, an acceptable scorch time is observed for the vulcanizates containing LC-Cys due to the effect of delayed vulcanization by rareearth ions.

LC-Cys increases the crosslink density of NR composites, and tensile strength increases with an increase in the crosslink density of the vulcanizates filled with LC-Cys. Regardless of the $\mathrm{ZnO}$ additions used, $\tan \delta$ at $T_{\mathrm{g}}$ of the vulcanized rubber containing LC-Cys was lower than that of the composites without LC-Cys due to the increase in crosslinking density. Also, the NR composites containing 2 phr of LCCys exhibit higher storage modulus at $25^{\circ} \mathrm{C}$ and $60^{\circ} \mathrm{C}$, which reflects that the addition of LC-Cys directly affects the stiffness of the vulcanizates. Rare-earth ions of LC-Cys can capture free radicals by thermooxidative aging processing. Consequently, the composites cured with LC-Cys present ideal mechanical properties during the aging process, although $\mathrm{ZnO}$ additions appear to decrease to a great extent.

\section{Data Availability}

Our data is not publicly available at this time, which involves follow-up work.

\section{Conflicts of Interest}

The authors declare that they have no conflicts of interest.

\section{Acknowledgments}

This work was financially supported by the National Natural Science Foundation of China (Grant no. 51634005).

\section{References}

[1] J. Kruželák, R. Sýkora, and I. Hudec, "Vulcanization of rubber compounds with peroxide curing systems," Rubber Chemistry and Technology, vol. 90, no. 1, pp. 60-88, 2017.

[2] C. V. Marykutty, G. Mathew, E. J. Mathew, and S. Thomas, "Studies on novel binary accelerator system in sulfur vulcanization of natural rubber," Journal of Applied Polymer Science, vol. 90, no. 12, pp. 3173-3182, 2010. 
[3] S. Palaty and R. Joseph, "Studies on xanthate/dithiocarbamate accelerator combination in NR/BR blends," Journal of Applied Polymer Science, vol. 103, no. 6, pp. 3516-3520, 2010.

[4] I. H. K. Samarasinghe, S. Walpalage, D. G. Edirisinghe, and S. M. Egodage, "Study on sulfur vulcanized natural rubber formulated with nitrosamine safe diisopropyl xanthogen polysulfide/tertiary butyl benzothiazole sulphenamide binary accelerator system," Progress in Rubber Plastics Recycling Technology, vol. 37, no. 3, pp. 190-202, 2020.

[5] F. Wei, Q. Zhang, W. Zhang, M. Huang, and Y. Luo, "Synthesis, characterization and vulcanizing properties of rare earth complexes with 2-mercaptobenthiazole," Journal of the Chinese Rare Earth Society, vol. 20, pp. 37-40, 2002.

[6] S. Wen, X. Zhang, S. Hu, L. Zhang, and L. Liu, "Influence of insitu reaction on luminescent properties of samarium- complex/hydrogenated acrylonitrile-butadiene composites," Polymer, vol. 50, no. 14, pp. 3269-3274, 2009.

[7] G. Heideman, R. N. Datta, J. W. M. Noordermeer, and B. van Baarle, "Influence of zinc oxide during different stages of sulfur vulcanization. Elucidated by model compound studies," Journal of Applied Polymer Science, vol. 95, no. 6, pp. 1388-1404, 2010.

[8] I. O. Adisa, V. L. Reddy Pullagurala, S. Rawat et al., "Role of cerium compounds in fusarium wilt suppression and growth enhancement in tomato (Solanum lycopersicum)," Journal of Agricultural and Food Chemistry, vol. 66, no. 24, pp. 59595970, 2018.

[9] M. A. Saifi, S. Sangomla, A. Khurana, and C. Godugu, "Protective effect of Nanoceria on cisplatin-induced nephrotoxicity by amelioration of oxidative stress and pro-inflammatory mechanisms," Biological Trace Element Research, vol. 189, no. 1, pp. 145-156, 2019.

[10] Q. Gao, K. Wang, and X. Wang, "Study on syntheses and anticoagulant action of rare earth nano-oxides $\backslash$ TDI-CS hybrid materials," Acta Chimica Sinica, vol. 70, no. 2, pp. 207-211, 2012.

[11] N. H. Ferreira, R. A. Furtado, A. B. Ribeiro et al., "Europiu$\mathrm{m}$ (III)-doped yttrium vanadate nanoparticles reduce the toxicity of cisplatin," Journal of Inorganic Biochemistry, vol. 182, no. 1, pp. 9-17, 2018.

[12] A. R. R. Menon, C. K. S. Pillai, and G. B. Nando, "Vulcanization of natural rubber modified with cashew nut shell liquid and its phosphorylated derivative-a comparative study," Polymer, vol. 39, no. 17, pp. 4033-4036, 1998.

[13] B. Ellis and G. N. Welding, "Estimation, from swelling, of the structural contribution of chemical reactions to the vulcanization of natural rubber. Part I. General Method," Rubber Chemistry and Technology, vol. 37, no. 2, pp. 563-570, 1964.

[14] M. G. Bawendi and K. F. Freed, "Systematic corrections to Flory-Huggins theory: polymer-solvent-void systems and binary blend-void systems," Journal of Chemical Physics, vol. 88, no. 4, pp. 2741-2756, 1988.

[15] A. N. Gaidadin, S. A. Safronov, M. Y. Kulikova, V. A. Navrotskii, D. A. Kutsov, and V. O. Kharlamov, "Assessing the structure of thermoplastic elastomers by the equilibrium swelling method," International Polymer Science and Technology, vol. 43, no. 1, pp. 9-14, 2016.

[16] A. H. Nellen and H. M. Sellers, "Correlation between Geer oven and natural aging of selected tire compounds," Industrial and Engineering Chemistry, vol. 21, no. 11, pp. 1019-1020, 2002.
[17] R. R. Wang, Z. Zheng, T. Jin, and R. J. Staples, "Coordination chemistry of lanthanides at "high" pH: synthesis and structure of the pentadecanuclear complex of europium (III) with tyrosine," Angewandte Chemie International Edition, vol. 38, no. 12, pp. 1813-1815, 1999.

[18] Y. Sun and S. Zhang, "Studies on L-cysteine complexes of lanthanide chlorides- its preparation, FT-IR and XPS," Chinese Journal of Applied Chemistry, vol. 6, no. 6, pp. 32-37, 1989.

[19] Zhaogang Liu, J. Zhao, M. Li, Y. Hu, J. Wu, and F. Feng, "Enhanced the thermal stability of polyvinyl chloride via synergistic effects of basic lanthanum tartrate with zinc stearate and pentaerythritol," Polymer Science Series B+, vol. 63, no. 2, pp. 182-190, 2021.

[20] A. Ramesh, H. Hasegawa, W. Sugimoto, T. Maki, and K. Ueda, "Adsorption of gold(III), platinum(IV) and palladium(II) onto glycine modified crosslinked chitosan resin," Bioresource Technology, vol. 99, no. 9, pp. 3801-3809, 2008.

[21] M. A. Ratcliff, E. E. Medley, and P. G. Simmonds, "Pyrolysis of amino acids. Mechanistic considerations," Journal of Organic Chemistry, vol. 39, no. 11, pp. 1481-1490, 1974.

[22] S. Li, W. Hao, Z. Liu et al., "Synthesis of cerium methionine and its effect on rubber vulcanization," Journal of Functional Materials, vol. 52, no. 5, pp. 5127-5134, 2021.

[23] M. Maciejewska and M. Siwek, "The influence of curing systems on the cure characteristics and physical properties of styrene-butadiene elastomer," Materials, vol. 13, no. 23, pp. 5329-5348, 2020.

[24] V. Ducháček, "Effect of zinc oxide concentration on the course of thiuram-accelerated sulfur vulcanization," Journal of Applied Polymer Science, vol. 20, no. 1, pp. 71-78, 1976.

[25] Y. Chen, Effects of Non-Rubber Substances in Natural Rubber Latex on Rubber Structure and Properties, Hainan University, Hainan, 2010.

[26] L. Li, Y. Bai, M. Lei, and L. Liu, "Progress in rubber vulcanization accelerator," Progress in Chemistry, vol. 27, no. 10, pp. 1500-1508, 2015.

[27] D. Lhamo and C. McMahan, "Effect of protein addition on properties of guayule natural rubber," Rubber Chemistry and Technology, vol. 90, no. 2, pp. 387-404, 2017.

[28] S. Bhattacharyya, C. Sinturel, O. Bahloul, M. L. Saboungi, S. Thomas, and J. P. Salvetat, "Improving reinforcement of natural rubber by networking of activated carbon nanotubes," Carbon, vol. 46, no. 7, pp. 1037-1045, 2008.

[29] M. N. Alam, S. K. Mandal, K. Roy, and S. C. Debnath, "Safe amine based zinc dithiocarbamates for the vulcanization of carbon black reinforced natural rubber," Journal of Applied Polymer Science, vol. 131, no. 6, pp. 596-602, 2014.

[30] J. M. Baldwin, D. R. Bauer, and K. R. Ellwood, "Rubber aging in tires. Part 1: field results," Polymer Degradation and Stability, vol. 92, no. 1, pp. 103-109, 2007.

[31] M. Maslowski, J. Miedzianowska, and K. Strzelec, "Natural rubber composites filled with crop residues as an alternative to vulcanizates with common fillers," Polymers, vol. 11, no. 6, pp. 972-989, 2019.

[32] J. Kruzelak, R. Dosoudil, and I. Hudec, “Thermooxidative aging of rubber composites based on NR and NBR with incorporated strontium ferrite," Journal of Elastomers and Plastics, vol. 50, no. 1, pp. 71-91, 2018.

[33] W. Zheng, Z. Jia, Z. Zhang, W. Yang, L. Zhang, and S. Wu, "Improvements of lanthanum complex on the thermal- 
oxidative stability of natural rubber," Journal of Materials Science, vol. 51, no. 19, pp. 9043-9056, 2016.

[34] C. Xie, Z. Jia, Y. Luo, and D. Jia, "Antioxidant effect of Sm(III) complex with 2-mercaptobenzimidazole rubber vulcanizates," Acta Polymerica Sinica, vol. 32, no. 3, pp. 320-326, 2011.

[35] Y. LUO, C. YANG, B. CHEN et al., "Thermal degradation of epoxidized natural rubber in presence of neodymium stearate," Journal of Rare Earths, vol. 31, no. 5, pp. 526-530, 2013.

[36] Y. Zou, Y. Sun, Y. Zhang et al., "Antioxidative behavior of a novel samarium complex in styrene-butadiene rubber/silica composites," Polymer Degradation and Stability, vol. 133, pp. 201-210, 2016. 